This item was submitted to Loughborough's Research Repository by the author.

Items in Figshare are protected by copyright, with all rights reserved, unless otherwise indicated.

\title{
Sleep duration and sleep efficiency in UK long distance heavy goods vehicle drivers
}

PLEASE CITE THE PUBLISHED VERSION

https://doi.org/10.1136/oemed-2021-107643

PUBLISHER

BMJ Publishing Group

VERSION

AM (Accepted Manuscript)

\section{PUBLISHER STATEMENT}

This article has been published in Occupational and Environmental Medicine, 2021 following peer review, and the Version of Record can be accessed online at https://doi.org/10.1136/oemed-2021-107643.

\section{LICENCE}

CC BY-NC 4.0

\section{REPOSITORY RECORD}

Sherry, Aron, Stacy Clemes, Yu-Ling Chen, Charlotte Edwardson, Laura Gray, Amber Guest, James King, et al.. 2021. "Sleep Duration and Sleep Efficiency in UK Long Distance Heavy Goods Vehicle Drivers". Loughborough University. https://hdl.handle.net/2134/15028128.v1. 


\section{SLEEP DURATION AND SLEEP EFFICIENCY IN UK LONG DISTANCE HEAVY 2 GOODS VEHICLE DRIVERS}

3 Dr. Aron P Sherry ${ }^{1,2}$ Dr. Stacy A Clemes ${ }^{1,2}$ Dr. Yu-Ling Chen ${ }^{1}$ Dr. Charlotte L. Edwardson ${ }^{2,3}$ 4 Prof. Laura J Gray ${ }^{4}$ Amber Guest ${ }^{1}$ Dr. James A King ${ }^{1,2}$ Dr. Alex V Rowlands ${ }^{2,3}$ Katharina 5 Ruettger $^{1}$ Dr. Mohsen Sayyah ${ }^{1}$ Dr. Veronica Varela-Mato ${ }^{1}$ Dr. Iuliana Hartescu

$7{ }^{1}$ School of Sport, Exercise and Health Sciences, National Centre for Sport and Exercise

8 Medicine, Loughborough University, Epinal Way, Loughborough, LE11 3TU

$9{ }^{2}$ National Institute for Health Research (NIHR) Leicester Biomedical Research Centre, 10 University Hospitals of Leicester NHS Trust and University of Leicester, Leicester, UK

$11{ }^{3}$ Diabetes Research Centre, University of Leicester, Leicester LE5 4PW, UK

$12{ }^{4}$ Department of Health Sciences, University of Leicester, Leicester, UK.

14 Corresponding Author:

15 Dr Aron Peter Sherry

16 School of Sport, Exercise and Health Sciences

17 National Centre for Sport and Exercise Medicine

18 Loughborough University

19 Epinal Way

20 Loughborough

21 LE11 3TU

22 a.p.sherry@lboro.ac.uk

2301509228462

24

25 Word count - 3340 Word limit: 3500

26

27 


\section{ABSTRACT}

\section{Objectives}

3 To profile sleep duration and sleep efficiency in UK long-distance heavy goods vehicle (HGV)

4 drivers and explore demographic, occupational and lifestyle predictors of sleep.

\section{Methods}

6 Cross-sectional analyses were carried out on 329 HGV drivers (98.5\% males) recruited across 7 an international logistics company within the midland's region, UK. Sleep duration and 8 efficiency were assessed via wrist-worn accelerometry (GENEActiv) over 8-days. Proportions 9 of drivers with short sleep duration ( $<6-h / 24-h$ and $<7-h / 24-h)$ and inadequate sleep efficiency $10(<85 \%)$ were calculated. Demographic, occupational and lifestyle data were collected via 11 questionnaire and device-based measures. Logistic regression assessed predictors of short 12 sleep duration and inadequate sleep efficiency.

\section{Results}

$1458 \%$ of drivers had a mean sleep duration of $<6-\mathrm{h} / 24-\mathrm{h}, 91 \%$ demonstrated $<7-\mathrm{h}$ sleep/24-h and $72 \%$ achieved $<85 \%$ sleep efficiency. Sleeping $<6$-h/24-h was less likely in morning (odds ratio [OR] 0.45, 95\% confidence interval [Cl] 0.21-0.94) and afternoon (OR 0.24, Cl 0.1017 0.60) shift workers (vs night) and if never smoked (vs current smokers) (OR 0.45, Cl-0.2218 0.92). The likelihood of sleeping <7-h/24-h reduced with age (OR 0.92, Cl 0.87-0.98). The 19 likelihood of presenting inadequate sleep efficiency reduced with age (OR 0.96, Cl 0.93-0.96) 20 and overweight body mass index category (vs obese) (OR 0.47, $\mathrm{Cl} 0.27-0.82$ ).

\section{Conclusions}

22 The high prevalence of short sleep duration and insufficient sleep quality (efficiency) rate 23 suggest many HGV drivers have increased risk of excessive daytime sleepiness, road traffic 24 accidents and chronic disease. Future sleep research in UK HGV cohorts is warranted given 25 the road safety and public health implications.

26

27 Abstract word count: 250 


\section{KEY MESSAGES}

\section{What is already known about this subject?}

3 - Internationally, HGV drivers are known to have insufficient sleep

4 - Insufficient sleep carries risks of daytime sleepiness, road traffic accidents, reduced mental

5 well-being and chronic disease in HGV drivers

6 - Accelerometer-measured sleep data during free living conditions is needed in UK HGV

7 drivers to build on the predominant self-reported evidence-base currently available

\section{What are the new findings?}

9 - Within a UK HGV sample, almost all drivers had short sleep duration ( $<7$-h) and almost 10 three quarters had inadequate sleep efficiency $(<85 \%)$ compared to National Sleep 11 Foundation recommendations

12 - Short sleep duration and inadequate sleep efficiency were predicted by shift type, smoking 13 status, age and/or body mass index category

14 How might this impact on policy or clinical practice in the foreseeable future?

- Further sleep research should develop and evaluate interventions targeting sleep behaviours in HGV drivers

- UK-based logistics companies should include more comprehensive assessments of sleep 18 behaviour and incorporate sleep surveillance as part of routine training and medical 19 evaluation procedures

20 - Weight management and sleep behaviour awareness training should also be considered 


\section{INTRODUCTION}

2 Long-distance heavy goods vehicle (HGV) drivers, responsible for transporting goods within

3 a vehicle in excess of 3.5 tonnes (gross vehicle weight) (1), work within hazardous conditions

4 that jeopardise their health and well-being $(2,3)$. Harmful occupational factors, such as shift

5 working and demanding delivery schedules $(2,4,5)$, and undesirable lifestyles, such as poor

6 nutritional intake, low levels of physical activity and sleep deprivation (5,6), culminate in an

7 increased risk of accidents, higher rates of chronic disease and reduced life expectancy

8 compared to general populations $(3,7,8)$.

9 Healthy sleep (e.g. $\geq 7-h / 24-h(9)$ ) is critical for long-distance HGV drivers' and other road user 10 safety $(7,10)$. Insufficient sleep (i.e. $<7$-h sleep duration), which can lead to daytime sleepiness,

11 fatigue and impaired vigilance, is responsible for a disproportionately high number of fatigue12 related road accidents involving HGV drivers $(8,10)$. Healthy sleep is also essential for well13 being and to avoid co-morbidities $(11,12)$. For instance, very short sleep (<6 hours/24-h) is 14 associated with all-cause mortality, diabetes mellitus, cardiovascular disease, obesity, lower 15 self-esteem and optimism compared to regularly obtaining 7-8-h/24-h sleep $(11,12)$. Given the 16 public health and road safety implications, sleep should be a priority lifestyle behaviour for 17 HGV drivers.

Adults should try to achieve 7-8-h/24-h of sleep for good health (13). Sleep efficiency, a measure of the actual time asleep whilst in bed, is used as an indicator of sleep quality and considered 'good' if $\geq 85 \%$ (9). In US and Australian HGV drivers, numerous studies have reported an average sleep duration of $<7-\mathrm{h} / 24-\mathrm{h}(7,14,15)$ and others have observed high proportions (e.g. $>40 \%$ ) of drivers reporting short sleep $(16,17)$. Sleep quality has been selfreported as 'poor' in around a fifth of US and European HGV drivers $(7,18,19)$, with $78 \%$ sleep efficiency reported in Australian drivers from device-based data (14). These sleep outcomes compare unfavourably to general populations $(20,21)$.

Sleep behaviour is influenced by multiple demographic, occupational and lifestyle factors. For instance, sleep duration and efficiency generally decrease with age (21), a potentially significant factor in the ageing workforce of UK HGV drivers (22). Shift workers show high rates of sleep disorders compared to conventional workers (23) and less HGV driving experience has been associated with poor sleep quality (19). Poor lifestyles, widespread in HGV drivers $(5,6)$, such as smoking, low levels of physical activity and obesity, are also associated with sleep disorders and sleep deprivation (24-26). Sleep research should explore the distribution of these factors in UK HGV drivers, to help effectively target sleep interventions. 
1 Most research examining sleep in HGV drivers has relied on self-report measures, which can 2 be prone to overestimation (21). Accelerometry is increasingly being utilised, as a convenient 3 and inexpensive method, in large population studies which assess longitudinal patterns in 4 sleep behaviour and health outcomes (e.g., UK Biobank, NHANES). Such sleep data can also 5 provide supplementary estimates of sleep characteristics that self-report cannot, such as 6 fragmented/accumulated sleep during time in bed (27). To date, no information on UK HGV 7 driver's sleep duration and efficiency collected via accelerometry has been reported.

8 Drawing on the needs identified in this at-risk population, our research aimed to 1) profile the 9 sleep behaviour of a UK HGV driver cohort, and 2) explore potential demographic, 10 occupational and lifestyle-related predictors of short sleep duration and inadequate sleep 11 efficiency. 


\section{METHODS}

\section{Study design, setting and participants}

3 This cross-sectional study utilised baseline data collected from long-distance HGV drivers 4 taking part in the 'Structured Health Intervention For Truckers (SHIFT)' study; a cluster 5 randomised controlled-trial. The full protocol is available elsewhere (28). Briefly, data 6 collection took place within an international logistics company. Participants were recruited 7 from 25 sites located across the midland's region of the UK ( $n=1502$ employed HGV drivers

8 in total across participating sites), operating within the transport, retail, hospitality, healthcare,

9 pharmaceutical, construction, oil and gas, and automotive industries. All drivers were eligible 10 to take part unless diagnosed with cardiovascular diseases, haemophilia, blood-borne viruses, 11 or had mobility limitations that prevented them from increasing daily physical activity (physical 12 activity was the primary outcome of the SHIFT trial). Ethical approval was obtained from the 13 Loughborough University Ethics Approvals Sub-Committee (Reference: R17-P063) and all 14 participants provided written informed consent.

\section{Measurements}

16 Data collection occurred between January 2018 and July 2019 at respective worksites during a 2-h assessment (undertaken by trained researchers), at the beginning or end of participants working shift. Participants self-reported demographic, occupational and lifestyle information including sex, date of birth, ethnicity, education, shift pattern, years worked as an HGV driver, weekly working hours, smoking status, alcohol intake, and chronotype (MorningnessEveningness Questionnaire short-version (MEQ) (29)). Height was measured without shoes using a portable stadiometer (Seca 206, Oxford, UK). Weight was determined via Tanita DC3605 scales (Tanita Corporation, Tokyo, Japan). Body mass index (BMI) was calculated as weight $(\mathrm{kg}) /$ height $^{2}\left(\mathrm{~m}^{2}\right)$. Daily steps were determined via an activPAL3 micro accelerometer (PAL Technologies Ltd, Glasgow UK) worn continuously for eight-days (following the health assessment) on the midline anterior aspect of the upper thigh (waterproofed using a nitrile sleeve and Hypafix [BSN Medical] dressing). Median number of daily steps were the outcome of interest from the activPAL data.

29 Sleep

30 Participants wore a tri-axial accelerometer (GENEActiv, ActivInsights Ltd, Kimbolton, UK) on 31 the non-dominant wrist continuously for eight-days (during work and non-work periods), following the health assessment, to estimate sleep duration and efficiency. The device collected data at $100 \mathrm{~Hz}$ with a $\pm 8 g$ dynamic range. Participants were provided with a daily log 
1 to record time into bed, sleep onset time (explained to the participant as 'lights out'), wake-up

2 time, out of bed time, working periods and any non-wear periods.

\section{Data processing}

4 GENEActiv devices were initialised and downloaded using manufacturer proprietary software 5 (GENEActiv v.3.1). Accelerometer files were processed in the $\mathrm{R}$ package GGIR version 1.8-0 6 (30) to generate sleep outcome variables. Sleep windows were guided by the self-reported 7 sleep onset time and out of bed time provided by the daily log. Where sleep log data were 8 missing, automated sleep window detection was used (31). Sleep duration within this window 9 was calculated using a validated sleep detection algorithm (27). Briefly, arm angle relative to 10 the horizontal plane is detected to determine sleep periods; a low frequency of changes in arm 11 angle can be identified as sleep if occurring within a specified sleep window period. The sleep 12 window is determined by the daily log (sleep onset and out-of-bed times) or the algorithm if 13 daily log data were not available (the longest block/series of sustained inactivity, with no more 14 than a 60-min gap between blocks, within a 24-h period (noon-noon)). This algorithm has 15 demonstrated high sensitivity and specificity in detecting sleep periods (27). A wear time of $16 \geq 16$ hours over a 24-h period was required to determine a valid night of sleep data (27). 17 Individual nights of data with a sleep window $>13-\mathrm{h}$ or $<2$-h or sleep duration $>12-\mathrm{h}$ or $<1-\mathrm{h}$ 18 were identified as erroneous and removed. Participants were included in the analysis if 19 providing $\geq 3$ nights of valid data. Supplementary file S1 includes two additional more stringent 20 quality control criteria and sensitivity analyses within these robust subsamples of data. 21 Variables of interest from GGIR analysis included sleep window onset ('lights out'), sleep 22 window end ('out of bed' time), sleep window duration (duration between 'lights out' and 'out 23 of bed' time), sleep duration (periods of sleep accumulated during the sleep window) and sleep 24 efficiency (sleep duration/window duration*100). Short sleep duration was identified as <6$25 \mathrm{~h} / 24-\mathrm{h}(12)$ and <7-h/24-h (9), and inadequate sleep efficiency as <85\% (9).

26 activPALs were initialised and downloaded using manufacturer proprietary software (activPAL 27 Professional v.7.2.38). Event files were generated and processed using the freely available 28 Processing PAL software (https://github.com/UOL-COLS/ProcessingPAL, version 1.3, 29 University of Leicester, (Leicester UK)), which uses a validated algorithm to determine waking wear time (32). Participants providing $\geq 10$ hours of valid waking wear time daily, on $\geq 3$ days, were included in the analysis. The first day of data was removed from the analysis.

\section{Statistical analysis}


1 Descriptive data were reported as mean and standard deviations (or median and interquartile

2 range), or numbers and percentages as appropriate. Continuous data were reported for age,

3 years as an HGV driver, average weekly working hours, and daily steps. Alcohol intake score,

4 a discrete variable, was calculated by combining scores from two 5-point items; how often do

5 you have a drink containing alcohol? (answers ranging from 'Never' to ' 4 or more times a

6 week') and How many units of alcohol do you have on a typical day when you are drinking?

7 (answers ranging from '1 or 2' to '10 or more'). Each item was scored 0-4 for a combined score

8 out of 8 (units-per-week could not be calculated from these two question items). Participants

9 were grouped for shift pattern (morning, afternoon, night or rotating), smoking status (never,

10 previous smoker, current smoker), BMI (normal $\left(20.0-24.9 \mathrm{~kg} / \mathrm{m}^{2}\right)$, overweight $\left(25-29.9 \mathrm{~kg} / \mathrm{m}^{2}\right)$,

11 obese $\left(\geq 30.0 \mathrm{~kg} / \mathrm{m}^{2}\right)$ ), and chronotype (based on MEQ scores: Eveningness $(<12)$,

12 Intermediate (12-17) and Morningness (>17) (33)). Due to inconsistent work times between

13 worksites for each shift pattern, it was not possible to provide clear definitions of shift types.

14 Differences in demographic, occupational and lifestyle factors between those who did or did

15 not provide valid GENEActiv data were compared using independent t-tests, Mann-Whitney

$16 U$ tests or Pearson chi-square tests.

17 Logistic regression assessed demographic, occupational and lifestyle predictors of three 18 outcomes: $<6-h / 24-h$ and $<7-h / 24-h$ sleep duration and $<85 \%$ sleep efficiency. Age, shift 19 pattern, years as an HGV driver, average weekly working hours, chronotype, smoking status, 20 alcohol intake, BMl category and valid nights of sleep data were independent variables 21 entered into each of the three models via forced entry. Statistical analyses were conducted using SPSS v.23 (SPSS Inc., Chicago, IL, USA). Statistical significance was set at $P<0.05$. 


\section{RESULTS}

$2386 \mathrm{HGV}$ drivers were recruited into the trial (25.7\% recruitment rate across participating work

3 sites) and underwent baseline measures. Of these, 329 provided valid GENEActiv data (85.2\%)

4 and are included in this analysis. Comparisons between those providing valid GENEActiv data

$5 \quad(n=329)$ and those who did not $(n=57)$ revealed significantly more daily steps in those not

6 providing valid data $(+1237$ steps, $P<0.05)$ and differences $(P<0.05)$ within smoking status and

7 chronotype categories. There was a smaller proportion of current smokers $(-16.7 \%, P<0.05)$ in

8 the group without valid data, more intermediate chronotypes $(+18.2 \%, P<0.05)$ and fewer

9 morning chronotypes $(-15.0 \%, P<0.05)$.

10 Table 1 provides details of the full sample $(n=329)$. Most participants were male, White British 11 ethnicity, married and educated to General Certificate of Secondary Education (GCSE) level.

$1290 \%$ reported working some form of shift pattern (i.e., deviation from conventional 8am-6pm

13 working hours). Most were morning shift workers, obese and morning chronotypes. 
1 Table 1. Sample characteristics. Data presented as number (percentage) or

2 mean \pm standard deviation unless otherwise stated.

\begin{tabular}{|c|c|}
\hline Variable & n (\%) / mean \pm SD* \\
\hline Full sample, n (\%) & $329(100)$ \\
\hline \multicolumn{2}{|l|}{ Sex } \\
\hline Male, n (\%) & $324(98.5)$ \\
\hline \multicolumn{2}{|l|}{ Age } \\
\hline Overall, mean $\pm \mathrm{SD}$, (years) & $47.8 \pm 4.9$ \\
\hline \multicolumn{2}{|l|}{ Ethnicity } \\
\hline White British, n (\%) & $261(79.3)$ \\
\hline Other White, n (\%) & $45(13.7)$ \\
\hline Other ethnicities ${ }^{\star *}, \mathrm{n}(\%)$ & $23(7.0)$ \\
\hline \multicolumn{2}{|l|}{ Marital Status } \\
\hline Married, n (\%) & $173(52.6)$ \\
\hline Co-habiting, n (\%) & $58(17.6)$ \\
\hline Single, $\mathrm{n}(\%)$ & $41(12.5)$ \\
\hline Other, n (\%) & $57(17.3)$ \\
\hline \multicolumn{2}{|l|}{ Education } \\
\hline GCSE or equivalent, $\mathrm{n}(\%)$ & $214(65.0)$ \\
\hline A-level or equivalent, $\mathrm{n}(\%)$ & $33(10.0)$ \\
\hline University degree or higher, $\mathrm{n}(\%)$ & $82(24.9)$ \\
\hline \multicolumn{2}{|l|}{ Shift pattern } \\
\hline Morning, $\mathrm{n}(\%)$ & $211(64.1)$ \\
\hline Afternoon, n (\%) & $35(10.6)$ \\
\hline Night, n (\%) & $63(19.1)$ \\
\hline Rotating, n (\%) & $19(5.8)$ \\
\hline \multicolumn{2}{|l|}{ Years worked as HGV driver } \\
\hline Overall, median \pm IQR & $15.0 \pm 8.6-25.0$ \\
\hline \multicolumn{2}{|l|}{ Hours worked per week } \\
\hline Overall, median \pm IQR & $48.0 \pm 45.0-50.0$ \\
\hline \multicolumn{2}{|l|}{ Steps per day (activPAL) $(n=298)^{* * *}$} \\
\hline Number of valid days, median $\pm I Q R$ & $8.0 \pm 7.0-8.0$ \\
\hline Valid waking wear time, median $\pm I Q R$, hours/day & $16.5 \pm 15.9-17.2$ \\
\hline Overall, median \pm IQR, steps/day & $8544 \pm 6902-10625$ \\
\hline \multicolumn{2}{|l|}{ Smoking status } \\
\hline Never smoked, n (\%) & $133(40.4)$ \\
\hline Previous smoker, n (\%) & $140(42.6)$ \\
\hline Current smoker, n (\%) & $56(17.0)$ \\
\hline \multicolumn{2}{|l|}{ Alcohol intake score } \\
\hline Overall, mean \pm SD & $3.7 \pm 2.1$ \\
\hline \multicolumn{2}{|l|}{ Body mass index (BMI) } \\
\hline Overall, median \pm IQR, BMI $\left(\mathrm{kg} / \mathrm{m}^{2}\right)$ & $29.8 \pm 27.0-33.2$ \\
\hline Normal weight $\left(19.5-24.9 \mathrm{~kg} / \mathrm{m}^{2}\right), \mathrm{n}(\%)$ & $37(11.2)$ \\
\hline Overweight $\left(25-29.9 \mathrm{~kg} / \mathrm{m}^{2}\right), \mathrm{n}(\%)$ & $134(40.7)$ \\
\hline Obese $\left(\geq 30 \mathrm{~kg} / \mathrm{m}^{2}\right), \mathrm{n}(\%)$ & $158(48.0)$ \\
\hline \multicolumn{2}{|l|}{ Chronotype } \\
\hline Evening, n (\%) & $28(8.5)$ \\
\hline Intermediate, $\mathrm{n}(\%)$ & $111(33.7)$ \\
\hline Morning, $\mathrm{n}(\%)$ & $190(57.8)$ \\
\hline
\end{tabular}

$3{ }^{*}$ Number (percentage)/mean (standard deviation).

$4{ }^{* *}$ Other Ethnicities group includes nine ethnic categories; Indian ( $\left.n=6\right)$, Black Caribbean $(n=4)$, Black African ( $\left.n=3\right)$, White Irish $5(n=3)$, White and Black Caribbean $(n=2)$, Other Asian $(n=2)$, White and Black African $(n=1)$, Other Black $(n=1)$, Chinese $(n=1)$.

$6{ }^{* *} \mathrm{~N}=33$ participants did not provide valid activPAL data, $\mathrm{n}=298$ included in the analysis. All other variables include a full

7 sample of data $(n=329)$. HGV, heavy goods vehicle; GCSE, General Certificate of Secondary Education 
1 Table 2 reports sleep data for the whole sample and by different occupational and lifestyle 2 factors. The sample demonstrated a mean sleep duration of 5.8 \pm 1.0 -h, with most drivers (58\%)

3 having a mean sleep duration $<6$-h/24-h and almost all (91\%) demonstrating $<7-\mathrm{h}$ sleep/24-h.

4 Almost three-quarters $(72.0 \%)$ demonstrated inadequate sleep efficiency ( $<85 \%)$.

5 Table 3 shows logistic regression models that include demographic, occupational and lifestyle6 related predictors of short sleep duration ( $<6-h$ and $<7-h$ ) and inadequate sleep efficiency $7(<85 \%)$. Drivers were less likely to sleep $<6-\mathrm{h} / 24-\mathrm{h}$ if morning or afternoon shift workers 8 compared to night shift workers and if never smoked compared to current smokers. The 9 likelihood of sleeping $<7-\mathrm{h} / 24-\mathrm{h}$ reduced with age. The likelihood of having inadequate $(<85 \%)$ 10 sleep efficiency reduced with age and in the overweight BMl category compared to obese. 
1Table 2. sleep characteristics in long-distance UK HGV drivers for the full sample and across occupational 2and behavioural groups. Data presented as number (percentage) or mean \pm standard deviation unless 3otherwise stated.

\begin{tabular}{|c|c|c|}
\hline Variable & $\mathrm{n}(\%) /$ mean $\pm \mathrm{SD}^{*}$ & \\
\hline Valid nights, $\mathrm{n} \pm \mathrm{SD}$ & $5.7 \pm 0.6$ & \\
\hline Sleep window onset, mean $\pm S D, 24-h$ & $23: 00 \pm 2.4$ & \\
\hline Sleep window end, mean \pm SD, 24-h & $06: 02 \pm 2.4$ & \\
\hline Sleep window duration, mean $\pm S D, h$ & $7.3 \pm 0.9$ & \\
\hline \multicolumn{3}{|l|}{ Sleep duration } \\
\hline Overall, mean $\pm \mathrm{SD}, \mathrm{h}$ & $5.8 \pm 1.0$ & \\
\hline$<6$ hours, $\mathrm{n}(\%)$ & $192(58.4)$ & \\
\hline$\geq 6$ hours, $n(\%)$ & $137(41.6)$ & \\
\hline$<7$ hours, $\mathrm{n}(\%)$ & $299(90.9)$ & \\
\hline$\geq 7$ hours, $\mathrm{n}(\%)$ & $30(9.1)$ & \\
\hline \multicolumn{3}{|l|}{ Sleep efficiency } \\
\hline Overall, median \pm IQR, sleep efficiency score $(\%)$ & $80.1 \pm 72.8-85.7$ & \\
\hline$<85 \%, \mathrm{n}(\%)$ & $237(72.0)$ & \\
\hline \multirow[t]{2}{*}{$\geq 85 \%, \mathrm{n}(\%)$} & $92(28.0)$ & \\
\hline & $\begin{array}{l}\text { Sleep duration }(h) \\
\text { mean } \pm \text { SD }\end{array}$ & $\begin{array}{l}\text { Sleep efficiency (\%) } \\
\text { median } \pm \text { IQR }\end{array}$ \\
\hline \multicolumn{3}{|l|}{ Shift pattern } \\
\hline Morning $(n=211)$ & $5.8 \pm 0.9$ & $80.7 \pm 74.2-85.8$ \\
\hline Afternoon $(n=35)$ & $5.9 \pm 1.1$ & $78.7 \pm 69.4-85.3$ \\
\hline Night $(n=63)$ & $5.4 \pm 1.0$ & $76.4 \pm 68.2-84.2$ \\
\hline Rotating $(n=19)$ & $5.9 \pm 1.2$ & $79.8 \pm 75.3-88.8$ \\
\hline \multicolumn{3}{|l|}{ Smoking status } \\
\hline Never smoked $(n=133)$ & $5.9 \pm 0.9$ & $80.2 \pm 73.3-87.3$ \\
\hline Previously smoked $(n=140)$ & $5.7 \pm 1.0$ & $79.8 \pm 71.1-85.4$ \\
\hline Current smoker $(n=56)$ & $5.6 \pm 1.0$ & $79.7 \pm 77.7-84.0$ \\
\hline \multicolumn{3}{|l|}{ Body mass index (BMI) } \\
\hline Normal weight $\left(19.5-24.9 \mathrm{~kg} / \mathrm{m}^{2}\right)(\mathrm{n}=37)$ & $5.9 \pm 1.1$ & $81.3 \pm 69.8-86.6$ \\
\hline Overweight weight $\left(25.0-29.9 \mathrm{~kg} / \mathrm{m}^{2}\right)(\mathrm{n}=134)$ & $5.9 \pm 1.0$ & $81.0 \pm 74.7-87.4$ \\
\hline Obese weight $\left(\geq 30.0 \mathrm{~kg} / \mathrm{m}^{2}\right)(\mathrm{n}=158)$ & $5.6 \pm 1.0$ & $78.7 \pm 71.3-84.5$ \\
\hline \multicolumn{3}{|l|}{ Chronotype } \\
\hline Evening $(n=28)$ & $5.7 \pm 1.1$ & $75.1 \pm 66.9-86.5$ \\
\hline Intermediate $(n=111)$ & $5.6 \pm 1.1$ & $78.8 \pm 71.5-84.3$ \\
\hline Morning $(n=190)$ & $5.9 \pm 0.9$ & $81.1 \pm 74.4-86.7$ \\
\hline
\end{tabular}

$4 \mathrm{~h}$, hours; IQR, interquartile range; BMI, body mass index. *Number (percentage)/mean (standard deviation). 
T1able 3. Logistic regression models including demographic, occupational and lifestyle-related predictors of short sleep duration (less tran 6-h and less than 7-h) and inadequate sleep efficiency (<85\%).

\begin{tabular}{|c|c|c|c|c|c|c|c|c|c|}
\hline & \multicolumn{3}{|c|}{$<6-h$} & \multicolumn{3}{|c|}{$<7-h$} & \multicolumn{3}{|c|}{$<85 \%$} \\
\hline & \multirow{2}{*}{$\begin{array}{c}\text { OR } \\
0.98\end{array}$} & \multicolumn{2}{|c|}{$(95 \% \mathrm{Cl})$} & \multirow{2}{*}{$\begin{array}{r}\text { OR } \\
0.92\end{array}$} & \multicolumn{2}{|c|}{$(95 \% \mathrm{CI})$} & \multirow{2}{*}{$\begin{array}{c}\text { OR } \\
0.96\end{array}$} & \multicolumn{2}{|c|}{$(95 \% \mathrm{Cl})$} \\
\hline Age, years & & $(0.95$ & 1.01) & & $(0.87$ & $0.98)$ & & $(0.93$ & $0.99)$ \\
\hline \multicolumn{10}{|l|}{ Shift type } \\
\hline Morning & 0.45 & $(0.21$ & $0.94)$ & 1.11 & $(0.32$ & $3.84)$ & 0.75 & $(0.34$ & 1.61) \\
\hline Afternoon & 0.24 & $(0.10$ & $0.60)$ & 0.42 & $(0.11$ & 1.67) & 0.87 & $(0.31$ & 2.44) \\
\hline Rotating & 0.40 & $(0.13$ & $1.28)$ & 0.59 & $(0.09$ & 3.87) & 0.56 & $(0.16$ & 1.95) \\
\hline Night & 1 & & & 1 & & & 1 & & \\
\hline Total HGV years & 1.00 & (0.97, & 1.03) & 1.03 & $(0.98$ & 1.07) & 1.00 & $(0.97$ & 1.03) \\
\hline Average weekly working hours & 1.00 & $(0.97$ & $1.04)$ & 0.99 & (0.93, & 1.05) & 0.98 & $(0.94$ & 1.02) \\
\hline Daily steps & 1.00 & $(1.00$ & $1.00)$ & 1.00 & $(1.00$ & 1.00) & 1.00 & $(1.00$ & 1.00) \\
\hline \multicolumn{10}{|l|}{ Smoking status } \\
\hline Never & 0.45 & $(0.22$ & $0.92)$ & 0.77 & $(0.22$ & $2.75)$ & 0.49 & $(0.22$ & 1.01) \\
\hline Previous & 0.67 & $(0.33$ & 1.36) & 0.72 & $(0.21$ & 2.47) & 0.66 & (0.30, & 1.48) \\
\hline Current & 1 & & & 1 & & & 1 & & \\
\hline Alcohol intake score & 0.97 & (0.87, & 1.09) & 0.94 & $(0.78$ & 1.14) & 1.03 & (0.91, & 1.17) \\
\hline \multicolumn{10}{|l|}{ BMI category } \\
\hline Normal & 0.55 & $(0.25$ & $1.20)$ & 0.60 & $(0.17$ & 2.12) & 0.53 & $(0.23$ & 1.25) \\
\hline Overweight & 0.67 & $(0.40$ & 1.11) & 0.69 & (0.29, & 1.63) & 0.47 & $(0.27$ & $0.82)$ \\
\hline Obese & 1 & & & 1 & & & 1 & & \\
\hline \multicolumn{10}{|l|}{ Chronotype } \\
\hline Morning & 0.46 & $(0.16$ & 1.33) & 0.65 & $(0.13$ & $3.20)$ & 0.68 & $(0.22$ & 1.01) \\
\hline Intermediate & 1.11 & $(0.64$ & 1.92) & 2.00 & $(0.70$ & $5.69)$ & 1.63 & $(0.88$ & $3.03)$ \\
\hline Evening & 1 & & & 1 & & & 1 & & \\
\hline Nights of valid sleep data & 0.83 & $(0.54$ & 1.26) & 1.09 & $(0.59$ & 2.03) & 1.06 & $(0.69$ & 1.62) \\
\hline
\end{tabular}

3 OR, odds ratio; $\mathrm{Cl}$, confidence interval; $\mathrm{HGV}$, heavy goods vehicle; $\mathrm{BMI}$, body mass index.

4 For clarity on continuous and discreet variables, using the <6-h model (short sleep) as an example, the likelihood of having less than 6-h sleep per 24 5 hours reduced by $2 \%$ with every year increase in age, reduced by $3 \%$ for every unit increase of alcohol score (this discreet variable has a total score of 8 ),

6 and reduced by $17 \%$ for every valid night of sleep data (although the $95 \%$ confidence intervals for each of these variables spanned 1.0). Total years as an

7 HGV driver, average weekly working hours and daily steps did not increase or decrease the likelihood of sleeping less than 6-h per 24 hours. 


\section{DISCUSSION}

2 This is the first study in the UK to profile the sleep behaviour of long-distance HGV drivers

3 using an accelerometer assessment of sleep. We found that more than half of drivers in this

4 study $(58 \%)$ had a mean sleep duration of $<6-\mathrm{h}$, and almost all $(91 \%)$ demonstrated $<7-\mathrm{h}$

5 sleep/24-h. Short sleep duration (<-6 or $<7-h)$ is associated with increased risk of premature

6 mortality, morbidity (12), reduced mental well-being (11), and road traffic accidents $(7,10)$.

7 Previous studies in US HGV drivers have reported a mean self-reported sleep duration of $<7$ -

8 h (7,15), a 60-min longer sleep duration compared to the present study (6.9-h (7) and 6.7-h

9 (15) vs 5.8-h) $(7,15)$. These differences may be partly due to self-reported measures

10 overestimating sleep duration, compared to accelerometer measures (14,21). For example,

11 Baulk et al. (14), using wrist-worn accelerometry in 37 Australian HGV drivers, observed an

12 average of 6.3-h sleep duration, compared to 7.7-h when self-reported. Although not an HGV

13 driver study, Zhu et al. (21), using the same wrist-worn accelerometry and sleep detection

14 procedures as the present study, observed almost identical proportions of middle-to-older-

15 aged UK males $(n=82,995)$ achieving <6-h/24-h (60\%) and <7-h/24-h (91\%) sleep duration,

16 respectively, as seen herein. This suggests sleep duration in UK HGV drivers, although short

17 for most, is comparable to other UK males within the same age groups. Nevertheless, our data

18 suggests that drivers require on average $\sim 80$ mins (17\%) additional sleep for reduced

19 morbidity risk and enhanced road safety $(7,12)$. More studies using wrist-worn accelerometry

20 are needed to confirm this, including longitudinal studies that account for temporal and 21 seasonal sleep variation.

22 Almost three-quarters $(72.0 \%)$ of drivers had a mean sleep efficiency of $<85 \%$ in this study.

23 Insufficient sleep quality (efficiency) is associated with reduced psychological well-being (9)

24 and an increased risk of road traffic accidents in HGV drivers (7). Our findings are consistent

25 with previous international evidence suggesting that insufficient sleep quality is highly

26 prevalent within this workforce. A small sample of Australian HGV drivers have exhibited a

27 mean sleep efficiency of $78 \%$ from wrist-worn accelerometry data (14). Approximately one fifth

28 of Italian (17.3\% n=526) (18) and Belgian (17.3\% n=476) (19) HGV drivers have self-reported

29 poor sleep quality previously. Zhu et al. (21) reported a mean sleep efficiency of $81 \%$ in middle-

30 to-older-aged UK males ( $n=82,995)$ compared to a median $80 \%$ efficiency in the present study.

31 This suggests that sleep efficiency is similar in UK HGV drivers compared to other similar32 aged UK males.

33 The low sleep efficiency in combination with the short sleep duration is important when 34 considering the sleep window (time spent in bed). A mean sleep window duration of 7.3-h 35 suggests that, albeit marginally, drivers on average provided themselves with sufficient time 
1 in bed to achieve $\geq 7-h$ of sleep but most were unsuccessful. Some drivers may present with 2 sleep disorders such as obstructive sleep apnoea or insomnia (34), but this was not captured 3 in this study. Future studies should account for these factors, although sleep disorders are 4 often undiagnosed within this occupational group (35). Sleep hygiene behaviours (i.e., 5 practices that optimise sleep) in UK cohorts, and the occupational barriers to healthy sleep 6 habits, also need to be explored using mixed-methods approaches to inform sleep 7 interventions.

8 Logistic regression analyses revealed different predictors of short sleep duration between the $9<6-\mathrm{h}$ and $<7-\mathrm{h}$ models. This may be partly explained by only $9.1 \%$ of drivers sleeping for $\geq 7-$ $10 \mathrm{~h} / 24-\mathrm{h}$, whereas $41.6 \%$ of drivers achieved $\geq 6-\mathrm{h} / 24-\mathrm{h}$, suggesting the $<6-\mathrm{h}$ model is a better 11 fit of the data. Within the $<6$-h model, morning and afternoon shift workers were $55 \%$ and $76 \%$ 12 less likely to have short sleep duration compared to night shift workers, respectively. Although 13 approximately $90 \%$ of the sample were shift workers, who are more likely to have sleep 14 disorders compared to those working conventional hours (i.e., 8am - 6pm) (23), our analysis demonstrated the greatest risk of short sleep was evident in night shift workers. Night shift workers are particularly vulnerable to circadian rhythm misalignment (36), resulting in reduced sleep duration and quality (23) and increased risk of fatal occupational accidents (37). These workers may benefit the most from countermeasures known to enhance circadian adaption and benefit sleep outcomes such as maximising work time rest periods and napping opportunities, or improving lifestyle behaviours (e.g. increased physical activity) (36). Also, within the $<6$-h model, the likelihood of short sleep duration reduced by $55 \%$ in those who never smoked compared to current smokers. This is unsurprising given smoking is associated with a host of sleep disorders (24). Contrary to previous evidence (21), increasing age reduced the likelihood of short sleep duration and inadequate sleep efficiency within the $<7-h$ and $<85 \%$ models, respectively. It could be that older drivers implemented better sleep hygiene practices through experience, and perhaps earned more favourable shift patterns over time (e.g., morning shifts) compared to younger age groups. Supplementary file $\mathrm{S} 2$, which reports sleep outcomes and shift types by age groups, broadly supports this argument. However, it should be noted that age was not a strong predictor in either the $<7-\mathrm{h}$ or $<85 \%$ models (OR 0.92 and 0.96, respectively). Nevertheless, if these trends are repeated in future studies, further qualitative research with older HGV drivers (e.g., >50 years of age) may illustrate effective sleep hygiene behaviours that younger less experienced drivers could benefit from.

Drivers who were overweight were $53.0 \%$ less likely to have inadequate sleep efficiency compared to drivers who were obese. UK HGV drivers have higher than nationally representative rates of obesity (28) which was reflected in our sample as almost half of drivers were obese (48.0\%). Sleep deprivation and obesity are bi-directional (26) and given the host 
1 of environmental and occupational triggers for weight gain (e.g., shift work, prolonged 2 sedentary driving, unhealthy food options at service stations) the two may exacerbate one 3 another over time within this workforce. Our analysis suggests that being overweight may 4 include better sleep efficiency compared to being obese, which would be an important outcome from preventing weight gain in HGV drivers if reaching a normal BMI category

6 through weight loss cannot be achieved.

7 Our findings suggest that UK HGV drivers are potentially sleep deprived which carries 8 important implications for UK road safety and public health. Further sleep research within UK 9 cohorts is critical to effectively inform UK workplace policy for HGV drivers. However, as part 10 of routine training and medical evaluation procedures, UK-based logistics companies should 11 include more comprehensive assessments of sleep behaviour (e.g., Epworth Sleepiness 12 Scale) and incorporate sleep surveillance (e.g., sleep logs, accelerometry). These approaches 13 will provide a better understanding of sleep deprivation and potentially detect undiagnosed 14 sleep disorders, common within this workforce (35). Furthermore, given the high prevalence 15 of obesity within UK HGV drivers (22), which is central to many chronic diseases and has a 16 bi-directional relationship with sleep (26), weight management and sleep behaviour 17 awareness training could be prudent workplace policies that warrant consideration.

18 A strength of this study is the use of a validated sleep detection process to profile sleep 19 outcomes. This study has good generalisability to other UK HGV drivers due to the breadth of 20 recruitment (25 worksites across the UK midlands region, operating within sub-contracts 21 across eight different industries). Another strength is the study sample, a priority, yet hard to 22 reach, occupational group for health interventions, given the array of health risk factors 23 observed. Limitations include the cross-sectional nature of the present analyses, all worksites 24 being located within a single parent logistics organisation and a potential recruitment bias for a health intervention study. However, the sample age (mean 47.8 years), sex distribution ( $98.5 \%$ males) and high rates of overweight and obesity compared to $45-54$ year old UK males $(88.7 \%$ vs $79.0 \%$ ) indicate that the present sample are representative of UK HGV drivers $(22,28)$.

28 Diagnosed sleep disorders were not captured, which would have enhanced the interpretation of sleep outcomes. We also acknowledge the limitations of a movement-based detection process to capture sleep which is a complex physiological process. Naps were not measured in this study, which anecdotally occurred within some shift workers and may have impacted sleep outcomes. Specifically, sleep duration per 24-h will have likely been underestimated in some early morning and night shift workers. Furthermore, sleep behaviours, such as insomnia or sleep latency, may have been misclassified as sleep if little arm/body movement occurred 35 (27). 
1 In conclusion, most drivers had short sleep duration and insufficient sleep quality, therefore 2 it is plausible that these drivers are at increased risk of excessive daytime sleepiness, road 3 traffic accidents and chronic disease. Given the implications for road safety and public health, 4 future research is warranted. Studies should explore sleep behaviour between work periods 5 and non-work periods to understand if and how drivers may compensate for sleep deprivation 6 between shifts. A greater understanding of sleep behaviours in this occupational group 7 should inform interventions designed to improve sleep and improve driver health and road 8 safety over the longer-term. 
1 Acknowledgements: The authors would like to thank all of the HGV drivers who participated 2 in this study.

3 Competing interests None declared.

$4 \quad$ Funding The data presented in this paper were collected as part of the 'Structured Health 5 Intervention For Truckers (SHIFT)' randomised controlled trial, which is funded by the NIHR 6 Public Health Research Programme (reference: NIHR PHR 15/190/42). The research was 7 also supported by the NIHR Leicester Biomedical Research Centre. The views expressed are 8 those of the authors and not necessarily those of the NHS, the NIHR or the Department of 9 Health and Social Care.

10

11 Contributors APS contributed to study data collection, data processing, study conception, 12 analysis and interpretation of the data, and primary manuscript preparation. IH and SAC 13 contributed to the study conception, interpretation of the data, and manuscript 14 preparation/revision. CLE, JAK and AVR were involved in data interpretation and revision of 15 the manuscript. LG was involved in the revision of the manuscript. YLC, AG, KR, MS and VVM 16 contributed to data collection and processing.

17 Disclaimer The views expressed are those of the authors and not necessarily those of the $18 \mathrm{NHS}$, the NIHR or the Department of Health and Social Care 


\section{REFERENCES}

1. The Freight Transport Association. Logistics Report 2019. London, 2019. Available from: https://www.santandercb.co.uk/factsheet/fta-logistics-report-2019.pdf.

2. Apostolopoulos $Y$, Sönmez S, Shattell MM, et al. Health survey of US long-haul truck drivers: work environment, physical health, and healthcare access. Work 2013;46(1):113-23. Available from https://doi.org/10.3233/wor-121553

3. Crizzle AM, Bigelow P, Adams D, et al. Health and wellness of long-haul truck and bus drivers: A systematic literature review and directions for future research. $J$ Transp Health 2017;1;7:90-109. Available from https://doi.org/10.1016/j.jth.2017.05.359

4. Caddick N, Varela-Mato V, Nimmo MA, et al. Understanding the health of lorry drivers in context: A critical discourse analysis. Health 2017;21(1):38-56. Available from https://doi.org/10.1177/1363459316644492

5. Sieber WK, Robinson CF, Birdsey J, et al. Obesity and other risk factors: the national survey of US long - haul truck driver health and injury. Am J Ind Med 2014;57(6):61526. Available from https://doi.org/10.1002/ajim.22293

6. Varela-Mato V, O'Shea O, King JA, et al. Cross-sectional surveillance study to phenotype lorry drivers' sedentary behaviours, physical activity and cardio-metabolic health. BMJ open. 2017;1;7(6). Available from https://doi.org/10.1136/bmjopen-2016013162

7. Lemke MK, Apostolopoulos $\mathrm{Y}$, Hege A, et al. Understanding the role of sleep quality and sleep duration in commercial driving safety. Accid Anal Prev. 2016;1;97:79-86. Available from https://doi.org/10.1016/j.aap.2016.08.024

8. Jackson $\mathrm{P}$, Hilditch $\mathrm{C}$, Holmes $\mathrm{A}$, et al. Fatigue and road safety: a critical analysis of recent evidence. Department for Transport, Road Safety Web Publication. 2011 Feb;21.

9. Ohayon M, Wickwire EM, Hirshkowitz $M$, et al. National Sleep Foundation's sleep quality recommendations: first report. Sleep health. 2017;1;3(1):6-19. Available from https://doi.org/10.1016/j.sleh.2016.11.006

10. Stern HS, Blower D, Cohen ML, Czeisler CA, Dinges DF, Greenhouse JB, Guo F, Hanowski RJ, Hartenbaum NP, Krueger GP, Mallis MM. Data and methods for studying commercial motor vehicle driver fatigue, highway safety and long-term driver health. Accident Analysis \& Prevention. 2019 May 1;126:37-42. Available from: https://doi.org/10.1016/j.aap.2018.02.021

11. Lemola S, Räikkönen K, Gomez V, et al. Optimism and self-esteem are related to sleep. Results from a large community-based sample. Int J Behav Med. 2013;20(4):567-71. Available from https://doi.org/10.1007/s12529-012-9272-z

12. Itani $\mathrm{O}$, Jike $\mathrm{M}$, Watanabe $\mathrm{N}$, et al. Short sleep duration and health outcomes: a systematic review, meta-analysis, and meta-regression. Sleep Med. 2017;1;32:246-56. Available from https://doi.org/10.1016/j.sleep.2016.08.006

13. Chaput JP, McNeil J, Despres JP, et al. Seven to eight hours of sleep a night is associated with a lower prevalence of the metabolic syndrome and reduced overall cardiometabolic risk in adults. PloS one. 2013;5;8(9):e72832. Available from https://doi.org/10.1371/journal.pone.0072832

14. Baulk SD, Fletcher A. At home and away: Measuring the sleep of Australian truck 
drivers. Accid Anal Prev. 2012;1;45:36-40. Available from https://doi.org/10.1016/j.aap.2011.09.023

15. Olson R, Thompson SV, Wipfli B, et al. Sleep, dietary, and exercise behavioral clusters among truck drivers with obesity: implications for interventions. J Occup Environ Med. 2016;58(3):314. Available from https://doi.org/10.1097/jom.0000000000000650

16. Hege A, Perko M, Johnson A, et al. Surveying the impact of work hours and schedules on commercial motor vehicle driver sleep. Saf Health Work. 2015;1;6(2):104-13. Available from https://doi.org/10.1016/j.shaw.2015.02.001

17. Lemke MK, Hege A, Perko M, et al. Work patterns, sleeping hours and excess weight in commercial drivers. Occ Med. 2015; 1;65(9):725-31. Available from https://doi.org/10.1093/occmed/kqv080.

18. Guglielmi O, Magnavita N, Garbarino S. Sleep quality, obstructive sleep apnea, and psychological distress in truck drivers: A cross-sectional study. Soc Psychiatry Psychiatr Epidemiol. 2018;53(5):531-6. Available from https://doi.org/10.1007/s00127017-1474-x

19. Braeckman L, Verpraet R, Van Risseghem M, et al. Prevalence and correlates of poor sleep quality and daytime sleepiness in Belgian truck drivers. Chronobiol Int. 2011;1;28(2):126-34. Available from https://doi.org/10.3109/07420528.2010.540363

20. Cassidy S, Chau JY, Catt M, et al. Cross-sectional study of diet, physical activity, television viewing and sleep duration in 233110 adults from the UK Biobank; The behavioural phenotype of cardiovascular disease and type 2 diabetes. BMJ Open. 2016;6(3):1-11. Available from https://doi.org/10.1136/bmjopen-2015-010038

21. Zhu G, Catt M, Cassidy S, et al. Objective sleep assessment in $>80,000$ UK mid-life adults: Associations with sociodemographic characteristics, physical activity and caffeine. PLoS One. 2019;14(12):1-14. Available from https://doi.org/10.1371/journal.pone.0226220

22. Health and Social Care Information Centre. Health Survey for England 2019: Adult and child overweight and obesity [Internet]. 2019. Available from: https://digital.nhs.uk/dataand-information/publications/statistical/health-survey-for-england/

23. Paech GM, Jay SM, Lamond N, et al. The effects of different roster schedules on sleep in miners. Appl Ergon [Internet]. Elsevier Ltd; 2010;41(4):600-6. Available from: http://dx.doi.org/10.1016/j.apergo.2009.12.017

24. Jaehne, A., Loessl, B., Barkai, Z., et al. Effects of nicotine on sleep during consumption, withdrawal and replacement therapy. Sleep Med Rev. 2009;13(5):363-377. Available from https://doi.org/10.1016/j.smrv.2008.12.003

25. Simpson L, McArdle N, Eastwood PR, et al. Physical inactivity is associated with moderate-severe obstructive sleep apnea. J Clin Sleep Med. 2015;11(10):1091-1099A. Available from https://doi.org/10.5664/jcsm.5078

26. Cooper CB, Neufeld E V., Dolezal BA, et al. Sleep deprivation and obesity in adults: A brief narrative review. BMJ Open Sport Exerc Med. 2018;4(1):1-5. Available from https://doi.org/10.1136/bmjsem-2018-000392

27. Van Hees VT, Sabia S, Anderson KN, et al. A novel, open access method to assess sleep duration using a wrist-worn accelerometer. PLoS One [Internet]. 2015;10(11):013. Available from: http://dx.doi.org/10.1371/journal.pone.0142533. 
28. Clemes SA, Varela Mato V, Munir F, et al. Cluster randomised controlled trial to investigate the effectiveness and cost-effectiveness of a Structured Health Intervention for Truckers (the SHIFT study): A study protocol. BMJ Open. 2019;9(11):1-13. Available from http://dx.doi.org/10.1136/bmjopen-2019-030175

29. Adan A, Almirall H. Morningness- Eveningness Questionnaire: a reduced scale. Pers Individ Differ. 1991;12(3):241-53. Available from https://doi.org/10.1016/01918869(91)90110-w

30. Migueles JH, Rowlands A V., Huber F, et al. GGIR: A Research Community-Driven Open Source R Package for Generating Physical Activity and Sleep Outcomes From Multi-Day Raw Accelerometer Data. J Meas Phys Behav. 2019;2(3):188-96. Available from https://doi.org/10.1123/jmpb.2018-0063

31. Van Hees VT, Sabia S, Jones SE, et al. Estimating sleep parameters using an accelerometer without sleep diary. Sci Rep. 2018;8(1):1-11. Available from https://doi.org/10.1038/s41598-018-31266-z

32. Winkler $\mathrm{AH}$, Bodicoat $\mathrm{DH}$, Healy $\mathrm{GN}$, et al. Identifying adults' valid waking wear time by automated estimation in activPAL data collected with a $24 \mathrm{~h}$ wear protocol. Physiol Meas. 2016;37(10). Available from https://doi.org/10.1088/0967-3334/37/10/1653

33. Metropolitan Transpoort Research Unit. Involvement in fatalities HGVs over 3 . 5tonnes compared to all traffic. 26.11.17. London, 2017 available from https://bettertransport.org.uk/sites/default/files/pdfs/26.11.17 Fatal HGV collision rates ten year tables.pdf

34. American Academy of Sleep Medicine. International Classification of Sleep Disorders. 3rd ed. Darien, IL; 2014.

35. Lemke MK, Apostolopoulos Y, Hege A, et al. Can subjective sleep problems detect latent sleep disorders among commercial drivers? Accid Anal Prev [Internet]. Elsevier; 2018;115(January):62-72. Available from: https://doi.org/10.1016/j.aap.2018.03.012

36. Boivin DB, Boudreau P. Impacts of shift work on sleep and circadian rhythms. Pathol Biol [Internet]. Elsevier Masson SAS; 2014;62(5):292-301. Available from: http://dx.doi.org/10.1016/j.patbio.2014.08.001

37. Åkerstedt $\mathrm{T}$, Knutsson $\mathrm{A}$, Westerholm $\mathrm{P}$, et al. Work organisation and unintentional sleep: Results from the WOLF study. Occup Environ Med. 2002;59(9):595-600. Available from https://doi.org/10.1136/oem.59.9.595 